\title{
Experimental studies on a diesel engine using mahua oil as fuel
}

\author{
M. Pugazhvadivu ${ }^{1}$ and G. Sankaranarayanan ${ }^{2}$ \\ ${ }^{1}$ Dept. of Mechanical Engg., Pondicherry Engg. College, Puducherry-605014, India \\ ${ }^{2}$ Dept. of Mechanical Engg., Melmaruvathur Engg. College, Melmaruvathur-603319, India \\ pv_pec@yahoo.com
}

\begin{abstract}
In this work mahua oil was used as an alternative fuel for diesel engine. The properties of mahua oil were determined. The performance and emissions of a single cylinder, stationary diesel engine was evaluated using mahua oil and compared with standard diesel operation. Mahua oil was preheated to $130^{\circ} \mathrm{C}$ and the effect of preheating on the engine performance and emissions were determined. The heat release rate of mahua oil was enhanced with preheating. The engine performance improved and smoke, $\mathrm{CO}$ and $\mathrm{HC}$ emissions decreased while the engine was running with preheated mahua oil. A marginal increase in $\mathrm{NO}_{x}$ emission was noted. It is concluded that Mahua oil preheated to $130^{\circ} \mathrm{C}$ can be used as diesel substitute under emergency situations.
\end{abstract}

Keywords: Mahua oil, preheating, engine performance, exhaust emissions.

\section{Introduction}

Diesel engines are used to power automobiles, locomotives, ships and irrigation pumps. It is also used widely to generate electric power. Diesel engines offer higher thermal efficiency and durability. Despite these advantages, the environmental pollution caused by diesel engines becomes a major concern throughout the world. Diesel engines produce smoke, particulate matter, oxides of nitrogen $\left(\mathrm{NO}_{\mathrm{x}}\right)$, oxides of carbon $\left(\mathrm{CO} \& \mathrm{CO}_{2}\right)$ and unburnt hydrocarbon $(\mathrm{HC})$. Several alternative fuels have been studied to either substitute diesel fuel partially or completely. Alternative fuels derived from biological sources provide a means for sustainable development, energy conservation, energy efficiency and environmental protection. Some of the alternative fuels explored are biogas, ethanol, vegetable oils etc,. The interest in using vegetable oils as alternative fuels for diesel engines originated from Rudolph diesel. He tested the engine using peanut oil over 100 years ago and it continued within the agricultural community as fuel for tractors, pumping water and other agricultural machineries. As an alternative fuel, vegetable oil is renewable and contains less sulfur. The combustion of vegetable oil produces negligible sulphurdioxide emissions and much less toxic emissions. In principle, vegetable oil is carbon neutral; the carbondioxide released by combustion is absorbed back for photosynthesis. Vegetable oil is biodegradable, safe to store and transport and does not cause environmental or health problems. Several vegetable oils of edible nature such as rapeseed oil, sunflower oil, cotton seed oil, palm oil, olive oil etc. and non-edible nature such as jatropha oil, mahua oil, karanja oil have been used as alternative fuel for diesel engines.

Vegetable oils when used in its crude form create operational and durability problems in direct injection diesel engines due to their high viscosity and low volatility. Diesel engines indicated good performance and emissions levels on short-term running conditions of less than 10 hours. Long term operations ended up with injector coking, ring sticking, gum deposits and thickening of lubricating oil (Adams et al., 1983; Ziejewski et al., 1986). Methods such as blending and preheating with other fuels have been studied to reduce the viscosity of vegetable oils. Biodiesel, the chemically altered form of biodiesel has also been investigated by several researchers (Kalligeros et al, 2003; Pugazhvadivu \& Rajagopan, 2009).

Barsic \& Humke (1981) have investigated the use of preheated vegetable oils as fuel for diesel engines and concluded that preheating to $75^{\circ} \mathrm{C}$ is essential to dissolve the wax and prevent the clogging of fuel filters. Ryan et al. (1984) have studied the effect of preheating vegetable oils. It has been reported that vegetable oil has to be preheated to a temperature of $140^{\circ} \mathrm{C}$ to reduce the viscosity, to improve the spray pattern, atomization and cetane rating of the fuel. Murayama et al. (1984) have investigated the engine performance by increasing the fuel inlet temperature to $200^{\circ} \mathrm{C}$. It has been reported that there was an increase in engine performance and reduction in carbon deposits build-up and piston ring sticking. Empirical relations have been established to estimate the viscosity of rapeseed oil, palm oil and their blends at different temperatures.

Bari et al. (2002) have investigated the use of preheated crude palm oil as fuel and concluded that preheating was essential for the smooth flow of fuel through the injection system. The effect of preheated rapeseed oil on the combustion characteristics of a single cylinder indirect injection diesel engine was studied by Nwafor (2003). It has been reported that with preheated fuel the peak pressure was similar to diesel fuel operation due to the changes in oil viscosity and improved droplet size. Preheating to $140^{\circ} \mathrm{C}$ was found to reduce the viscosity of vegetable oil and improve the engine
Research article

CIndian Society for Education and Environment (iSee)
"Biofuel"

http://www.indjst.org
Pughazvadivu \& Sankaranarayanan Indian J.Sci.Technol. 

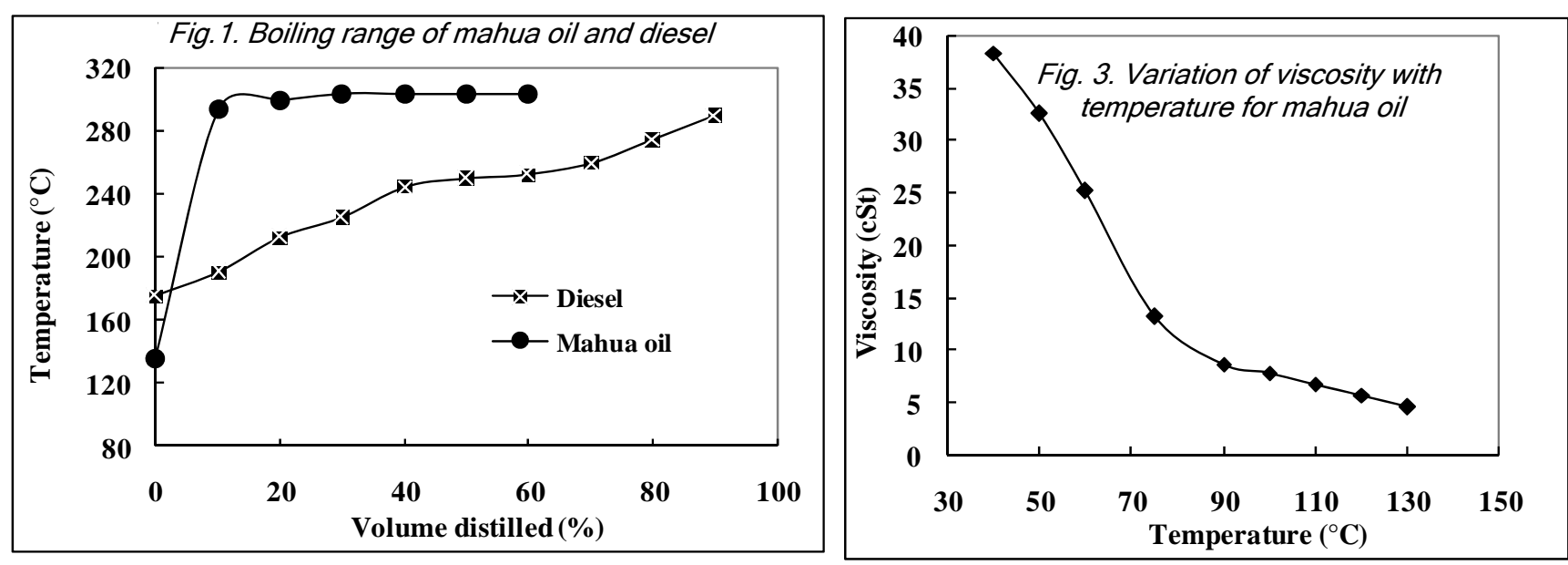

Fig. 2. Experimentalsetup

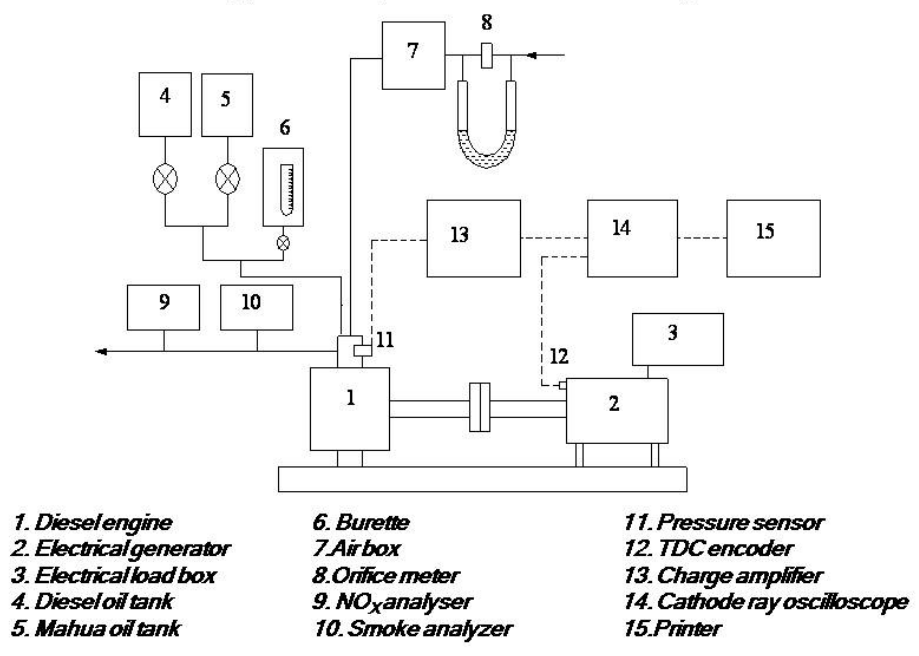

Fig. 4. Heat release rate with diesel, mahua oil $\&$ preheated mahua oil

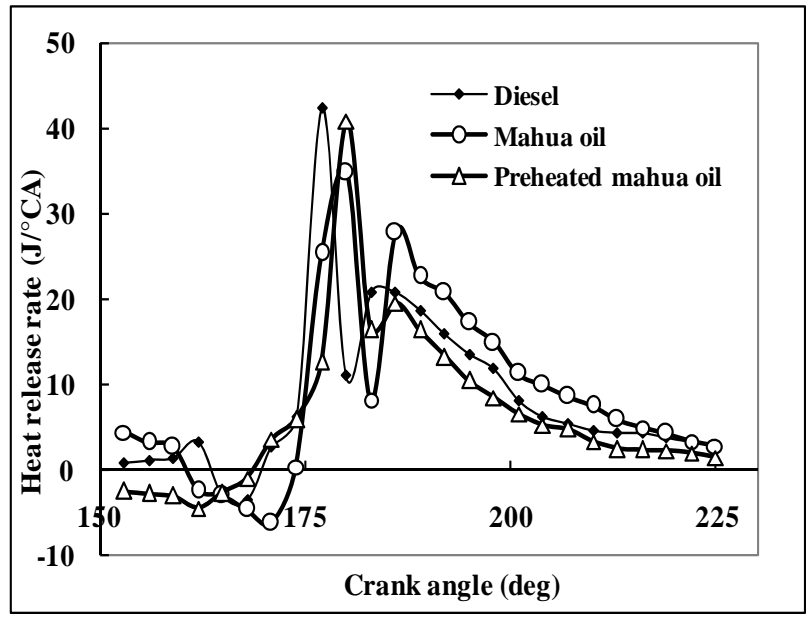

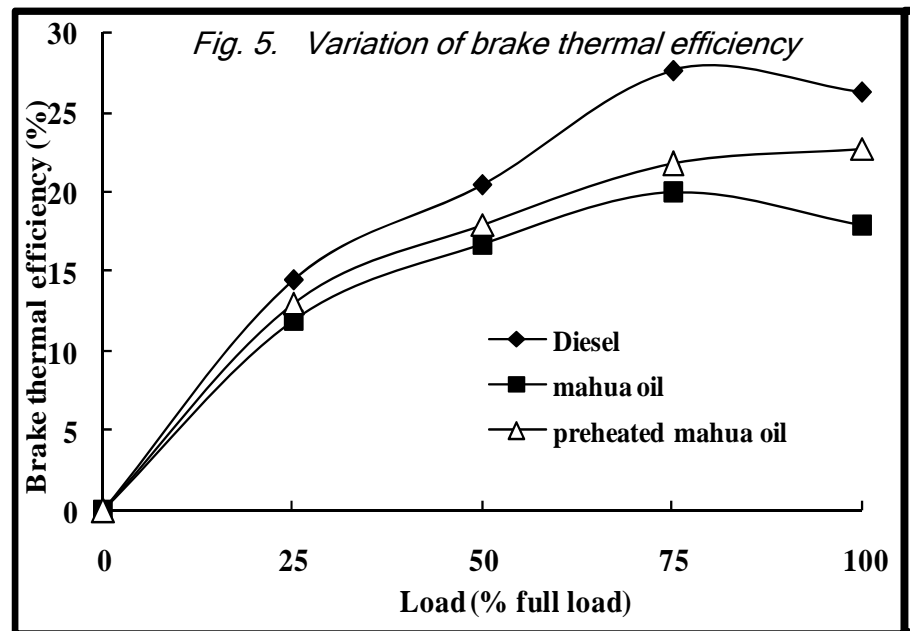

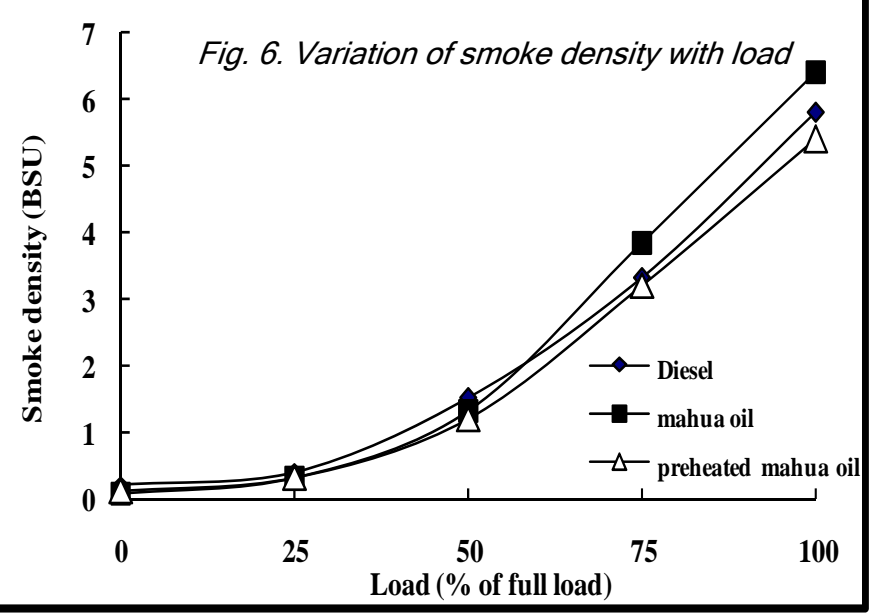


performance and emission levels (Pugazhvadivu \& Jeyachandran, 2005).

The objective of the present work was to reduce the viscosity of mahua oil by preheating to $130^{\circ} \mathrm{C}$ and investigate the engine performance and emissions with preheated mahua oil. The engine performance and emission results were compared with mahua oil and baseline diesel fuel operation.

\section{Materials and methods}

Mahua oil is obtained from the seeds of madhuca indica, a deciduous tree which can grow in semi-arid, tropical and sub-tropical areas. It grows even on rocky, sandy, dry shallow soils and tolerates water logging conditions. Mahua oil was procured from an oil mill. The oil was filtered to remove the impurities. Diesel fuel was used as baseline fuel. The

Table 1. Comparison of properties of mahua oil \& diesel

\begin{tabular}{|l|c|c|}
\hline \multicolumn{1}{|c|}{ Property } & Mahua oil & Diesel \\
\hline $\begin{array}{l}\text { Kinematic viscosity } \\
\text { @ } 40^{\circ} \mathrm{C}(\mathrm{cSt})\end{array}$ & 38.4 & 4.1 \\
\hline $\begin{array}{l}\text { Density @ 30 } \\
\left(\mathrm{kg} / \mathrm{m}^{3}\right)\end{array}$ & 912 & 840 \\
\hline Flash point $\left({ }^{\circ} \mathrm{C}\right)$ & 186 & $51^{\circ} \mathrm{C}$ \\
\hline Pour point in $\left({ }^{\circ} \mathrm{C}\right)$ & $11^{\circ} \mathrm{C}$ & $15^{\circ} \mathrm{C}$ \\
\hline $\begin{array}{l}\text { Net calorific value } \\
(\mathrm{kJ} / \mathrm{kg})\end{array}$ & 37082 & 43600 \\
\hline Acidity $(\mathrm{mg} \mathrm{KOH} / \mathrm{gm})$ & 28.9 & 0.20 \\
\hline Ash $(\%)$ & 0.10 & 0.01 \\
\hline Carbon residue (\%) & 0.46 & 0.30 \\
\hline Moisture (\%) & 0.09 & - \\
\hline
\end{tabular}

Vol. 3 No. 7 (July 2010)

ISSN: 0974- 6846 properties of mahua oil used in the present investigation are presented in Table 1. The viscosity was determined at different temperatures using redwood viscometer to find the effect of temperature on the viscosity of mahua oil. The viscosity of mahua oil was found to be 9 times higher than that of diesel fuel. The high viscosity of mahua oil may be due to its larger molecular weight compared to diesel. The flash point of mahua oil was higher than diesel and hence it is safer to store. The boiling range of mahua oil and diesel are shown in Fig. 1. It is seen that the boiling range of mahua oil was different from that of diesel. This may be due to the presence of components of high boiling point in mahua oil and their poor volatility characteristics.

\section{Experimental set up and procedure}

The experimental set up used in this investigation is shown in Fig. 2. It consists of a single cylinder, four stroke, constant speed, water cooled, direct injection compression ignition engine with hemispherical open combustion chamber developing $3.7 \mathrm{~kW}$ at $1500 \mathrm{rpm}$. The engine has a bore of $80 \mathrm{~mm}$, stroke of $110 \mathrm{~mm}$ and a compression ratio of 16.5. The fuel injection system of the engine comprised of a plunger type pump with an injector having three spray holes, each $0.28 \mathrm{~mm}$ diameter. The injector needle lift pressure and fuel injection timing of the engine were 185 bar and $27^{\circ} \mathrm{bTDC}$ respectively. The engine was coupled to an electrical generator and loaded by variable resistance loading bank. This type of engine is widely used as a prime-mover for operating water pumps in rural farms and the same model engine is befitted for small electric power generation systems.

The engine power output was measured using an ammeter and voltmeter. Thermocouples were used to measure the inlet and outlet temperature of cooling water.
The air intake flow rate was measured using an orifice meter and a water manometer. The orifice meter was mounted on a large surge tank which was used to attenuate the air flow pulses. Two fuel tanks were used one for mahua oil and another for diesel fuel. The volumetric flow rate of fuel was measured using a burette and a stop watch. The sample of exhaust gas was fed to a combustion gas analyzer (MRU Germany) to measure the gaseous emissions like $\mathrm{NO}_{x}, \mathrm{HC}$ and $\mathrm{CO}$. In addition, a Bosch smoke density meter was used to measure smoke density in the exhaust. A watercooled piezoelectric pressure transducer of range $0-250$ bar was used for in-cylinder pressure measurement. A crank angle encoder with top dead centre (TDC) marker was used to sense the position of TDC. The output of the crank angle encoder and pressure transducer was send to a charge amplifier. The cylinder pressure and crank angle signals were then fed to a cathode ray oscilloscope and a printer. The net heat release rate was calculated using the cylinder pressure and crank angle data observed from cylinder pressure and crank angle diagram by using first law of thermodynamics.

Fig. 3 shows the viscosity of mahua oil at different temperatures. It is seen in the Fig. 3 that the viscosity was reduced to $4.6 \mathrm{cSt}$ at $130^{\circ} \mathrm{C}$ and found to be almost equal to diesel at $40^{\circ} \mathrm{C}$. Hence, in this investigation a temperature of $130^{\circ} \mathrm{C}$ was maintained for preheating mahua oil flowing through the high pressure fuel line with the help of a manually operated electrical heating arrangement.

The engine performance and emissions tests were conducted with diesel fuel, mahua oil and mahua oil preheated to $130^{\circ} \mathrm{C}$. The fuel level in the fuel tank, flow of cooling water, level of lubricant in the engine oil sump were checked before starting the engine. The engine was started with diesel and warmed up. Mahua oil was admitted into the cylinder at the manufacturer recommended injection timing. In order to maintain the engine speed constant at $1500 \mathrm{rpm}$, the flow rate of mahua oil was reduced by adjusting the fuel injection pump control rack. The engine was allowed to reach steady state at each test and observations were recorded for output voltage, output current, time taken for $20 \mathrm{cc}$ of fuel consumption, $\mathrm{NO}_{x}, \mathrm{HC}, \mathrm{CO}$ and smoke density. All the observations were taken for $0 \%, 25 \%, 50 \%, 75 \%$ and $100 \%$ of full load on the engine. The results of the engine performance and emission parameters were investigated and presented in the following section. 
Results and discussion

Fig. 4 shows the variation of net heat release rate with crank angle using mahua oil, preheated mahua oil and

Fig. 7. Variation of hydrocarbon concentration with load

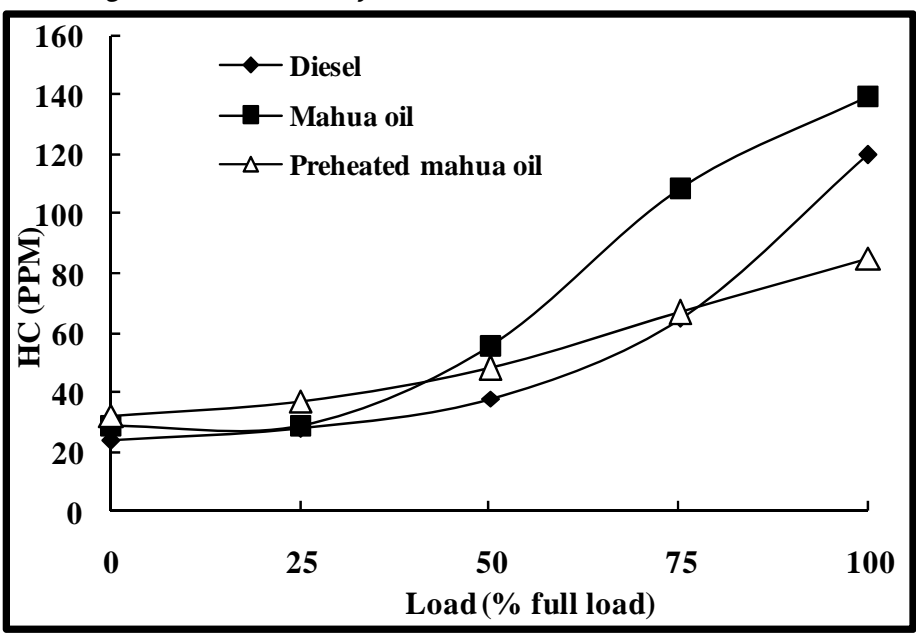

Fig. 8. Variation of carbonmonoxide concentration with load

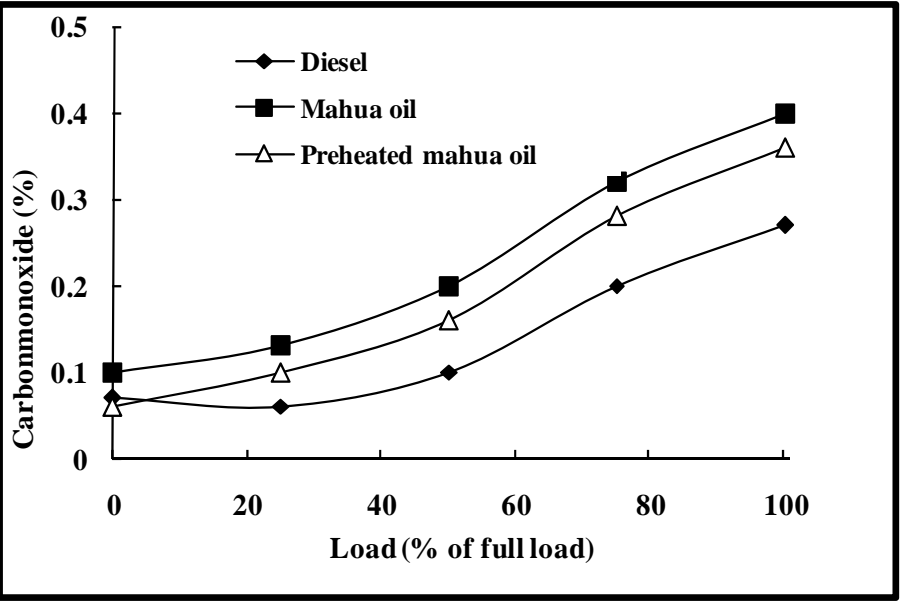

Fig. 9. Variation of $\mathrm{NO}_{x}$ concentration with load

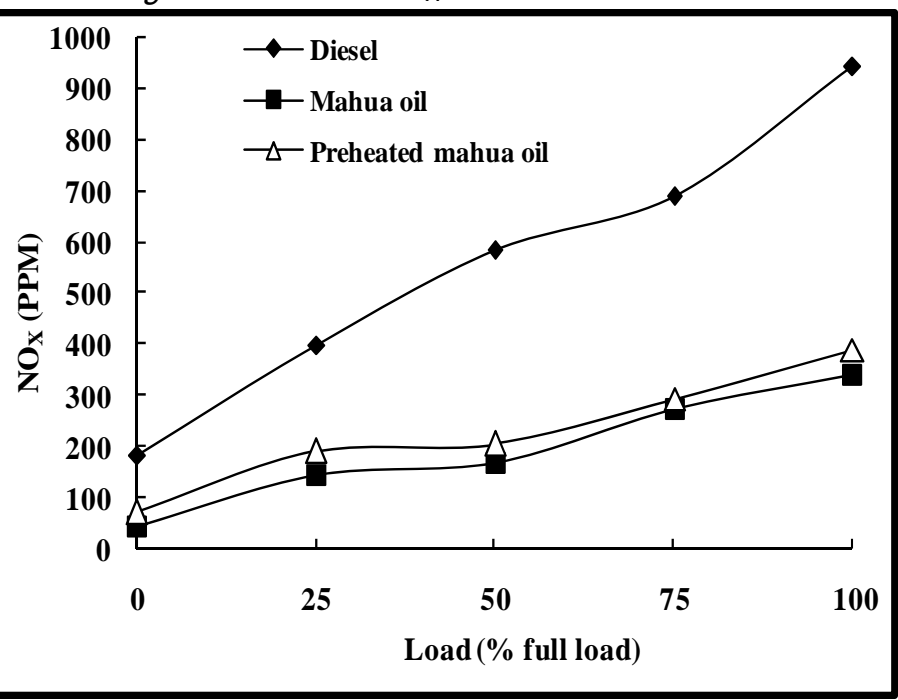

diesel at $75 \%$ of full load. It is seen that the maximum heat release rate occurred at the premixed combustion phase for all the fuels. It is also seen that the quantity of diffusive combustion was higher for mahua oil due to slowness in the burning of non-volatile components of mahua oil. The heat release diagram also shows a shorter premixed and longer diffusive combustion phase for mahua oil. This trend indicates that mahua oil vaporize and burns at a slower rate than diesel fuel. The maximum heat release rate using mahua oil was 34 $\mathrm{J} /{ }^{\circ} \mathrm{CA}$. compared to $42 \mathrm{~J} /{ }^{\circ} \mathrm{CA}$ using diesel. The decrease in heat release rate may be due to the poor volatile characteristics and lower calorific value of mahua oil. Fig 4 also shows the heat release rate using preheated mahua oil. It is seen that the maximum heat release rate has improved with preheating. The maximum heat release rate was $41 \mathrm{~J} /{ }^{\circ} \mathrm{CA}$ for preheated mahua oil, while it was $34 \mathrm{~J} /{ }^{\circ} \mathrm{CA}$ using mahua oil without preheating. The improvement in heat release rate may be due to the better spray and better air entrainment and improvement in volatile characteristics of mahua oil with preheating.

Fig. 5 shows the variation of brake thermal efficiency of the engine using diesel, mahua oil and preheated mahua oil. The engine thermal efficiency was lowered when it was running with mahua oil. The maximum thermal efficiency using mahua oil was $20 \%$ as against $28 \%$ with diesel at $75 \%$ load. The poor combustion behavior due to lower volatility and higher molecular weight caused a decrease in thermal efficiency compared to diesel. Fig. 5 also shows that the thermal efficiency was improved with preheated mahua oil. The reduction in viscosity of mahua oil with preheating caused better evaporation and mixing with air resulting in more complete fuel combustion. The maximum thermal efficiency $(22.8 \%)$ was obtained at full load using preheated mahua oil.

Fig. 6 shows the variation of smoke density with engine load. It is found that the smoke density of the engine with mahua oil operation was higher than diesel. This negative effect is mainly due to the high viscosity and poor volatility of mahua oil compared to diesel. The high viscosity and poor volatility of mahua oil caused poor fuel injection and mixing characteristics and incomplete combustion. Further, the mean diameter fuel droplet was higher for vegetable oil than diesel. The smoke density was higher at full load and it was 6.4 BSU with mahua oil operation. It is also seen from Fig. 6, that the smoke density was reduced with preheating. The smoke density was 5.4 BSU with preheated mahua oil operation. The reduction in smoke density may be due to the reduction in viscosity and subsequent improvement in spray and fuel air mixing causing good combustion. The results show that higher reduction in smoke density was achieved at part and full load conditions. However, only a marginal reduction was observed at low loads. This may be due to the dilution effect caused by the presence of excess air available at low loads.
Research article

CIndian Society for Education and Environment (iSee)
Pughazvadivu \& Sankaranarayanan Indian J.Sci.Technol. 
Fig. 7 shows the variation $\mathrm{HC}$ concentration with diesel, mahua oil and preheated mahua oil. It is seen that with mahua oil operation the $\mathrm{HC}$ concentration was higher compared to diesel. It is seen that the $\mathrm{HC}$ emission was higher at all loads with mahua oil. The poor injection of mahua oil and its improper mixing with air during preparation phase resulted in incomplete combustion and higher $\mathrm{HC}$ emission. It is seen that the $\mathrm{HC}$ emission was lowered for mahua oil combustion with preheating. Preheating caused more complete combustion of mahua oil. The $\mathrm{HC}$ emission was $85 \mathrm{ppm}$ with preheating compared to mahua oil (140 ppm) and diesel (120 ppm) at full load.

Fig. 8 shows the variation of $\mathrm{CO}$ concentration at various loads on the engine. The $\mathrm{CO}$ concentration was higher with mahua oil operation compared to diesel at all loads. This was due to the improper mixing of mahua oil with air. It is seen that the $\mathrm{CO}$ concentration reduced significantly with preheating mahua oil. It was reduced from $0.4 \%$ with mahua oil to $0.36 \%$ with preheating mahua oil to $130^{\circ} \mathrm{C}$.

Fig. 9 shows the variation of $\mathrm{NO}_{x}$ concentration at various loads for diesel, mahua oil and mahua oil preheated to $130^{\circ} \mathrm{C}$. This may be due to lower heat release rate in premixed phase of mahua oil resulting in lower maximum temperature in the combustion chamber. It is seen that at full load the $\mathrm{NO}_{x}$ emission was lower by about $60 \%$ compared to that of diesel. It is seen that the $\mathrm{NO}_{x}$ concentration increase with preheating mahua oil. The increase in $\mathrm{NO}_{x}$ concentration may be attributed to the increase in heat release rate with preheating. The $\mathrm{NO}_{x}$ concentration at maximum load increased by $13 \%$ with mahua oil preheated to $130^{\circ} \mathrm{C}$ compared to mahua oil without preheating. However, the $\mathrm{NO}_{x}$ emission was significantly lower with preheated mahua oil compared to diesel at all power outputs.

\section{Conclusions}

Mahua oil preheated to $130^{\circ} \mathrm{C}$ gives higher thermal efficiency. Preheating to $135^{\circ} \mathrm{C}$ gives lower smoke and $\mathrm{HC}$ emissions compared to that of diesel. Hence, preheated mahua oil can be used as an alternative fuel for diesel.

\section{References}

1. Adams C, Peters JF, Rand MC, Schroer BJ and Ziemke MC (1983) Investigation of soybean oil as a diesel fuel extender: Endurance tests. JAOCS. 60, 1574-1579.

2. Bari S, Lim TH and Yu CW (2002) Effect of preheating crude palm oil on injection system performance and emissions of a diesel engine. Renew. Energy. 77, 339351.

3. Barsic NJ and Humke AL (1981) Performance and emissions characteristics of a naturally aspirated diesel engine with vegetable oil fuels. SAE. 810262, 1173-1187.
4. Kalligeros S, Zannikos F, Stournas S, Lois E, Anastopoulos G, Teas $\mathrm{CH}$ and Sakellaropoulos F (2003) An investigation of using biodiesel/marine diesel blends on the performance of a stationary diesel engine. Biomass Bioenerg. 24, 141-149

5. Murayama T, Oh Y, Miyamoto N, Chikahisa T, Takagi $\mathrm{N}$ and Itow K (1984) Low carbon flower build-up, low smoke and efficient diesel operation with vegetable oil by conversion into monoesters and blending with diesel or alcohol. SAE. 841161, 5.292-5.301.

6. Nwafor OMI (2003) The effect of elevated fuel inlet temperature on performance of diesel engine running on neat vegetable oil at constant speed conditions. Renew. Energy. 28, 171-181.

7. Pugazhvadivu M and Jeyachandran K (2005) Investigations on the performance and exhaust emissions of a diesel engine using preheated waste frying oil as fuel. Renew. Energy. 30, 2189-2202.

8. Pugazhvadivu M and Rajagopan S (2009) Investigations on a diesel engine fuelled with biodiesel blends and diethyl ether as an additive. Indian J. Sci. Technol. 2 (5), 31-35. Domain site: http://www.indjst.org.

9. Ryan TW, Dodge TG and Callahan TJ (1984) The effect of vegetable oil properties on injection and combustion characteristics in two different diesel engines. JAOCS. 61, 1610-1619.

10.Ziejewski M, Goettler H and Pratt GL (1986) Influence of vegetable oil based alternative fuels on residue deposits and components wear in a diesel engine. SAE. 860302, 297- 307. 